\title{
Bilirubin Exerts Additional Toxic Effects in Hypoxic Cultured Neurons from the Developing Rat Brain by the Recruitment of Glutamate Neurotoxicity
}

\author{
STÉPHANIE GROJEAN, VALÉRIE LIEVRE, VIOLETTE KOZIEL, PAUL VERT, AND \\ JEAN-LUC DAVAL
}

Université Henri Poincaré, 54013 Nancy Cédex, France

\begin{abstract}
Both hypoxia and bilirubin are common risk factors in newborns, which may act synergistically to produce anatomical and functional disturbances of the CNS. Using primary cultures of neurons from the fetal rat brain, it was recently reported that neuronal apoptosis accounts for the deleterious consequences of these two insults. To investigate the influence of hypoxia, bilirubin, or their combination on the outcome of neuronal cells of the immature brain, and delineate cellular mechanisms involved, 6-d-old cultured neurons were submitted to either hypoxia $(6 \mathrm{~h})$, unconjugated bilirubin $(0.5 \mu \mathrm{M})$, or to combined conditions. Within 96 h, cell viability was reduced by $22.7 \%$ and $24.5 \%$ by hypoxia and bilirubin, respectively, whereas combined treatments decreased vital score by $34 \%$. Nuclear morphology revealed $13.4 \%$ of apoptotic cells after hypoxia, $16.2 \%$ after bilirubin, and $22.6 \%$ after both treatments. Bilirubin action was specifically blocked by the glutamate receptor antagonist MK801 , which was without effect on the consequences of hypoxia. Temporal changes in $\left[{ }^{3} \mathrm{H}\right]$ leucine incorporation rates as well as beneficial effects of cycloheximide reflected a programed phenomenon dependent upon synthesis of selective proteins. The presence of bilirubin reduced hypoxia-induced alterations of cell energy metabolism, as reflected by $2-\mathrm{D}-\left[{ }^{3} \mathrm{H}\right]$ deoxyglucose incor-
\end{abstract}

\section{ABSTRACT}

poration, raising the question of free radical scavenging. Measurements of intracellular radical generation, however, failed to confirm the antioxidant role of bilirubin. Taken together, our data suggest that low levels of bilirubin may enhance hypoxia effects in immature neurons by facilitating glutamate-mediated apoptosis through the activation of $N$-methyl-D-aspartate receptors.

(Pediatr Res 49: 507-513, 2001)

Abbreviations
CHX, cycloheximide
DAPI, 4,6-diamidino-2-phenylindole
2-DG, 2-D-deoxyglucose
DHR, dihydrorhodamine 123
MK-801, (+)-5-methyl-10,11-dihydro-5H-diben
[a,d]-cycloheptene-5,10-imine maleate
MTT, 3-[4,5-dimethylthiazol, 2-yl]-2,5-diphenyl
bromide
NBQX, 1,2,3,4-tetrahydroxy-6-nitro-2,3-dioxo-
benzo(f)quinoxaline, 7-sulfonamide isodium
NMDA, $N$-methyl-D-aspartate
TCA, trichloroacetic acid

Cerebral hypoxia remains a significant risk for neonatal morbidity and mortality, as well as long-term neurologic sequelae such as cerebral palsy, mental retardation, or seizure disorders $(1,2)$. Although lack of oxygen has been associated with neuronal degeneration $(3,4)$, it was not clear whether hypoxia itself, without the influence of combined ischemia, kills brain cells. In contrast to studies in intact animals, which are often difficult to interpret due to a number of confounding variables, cell culture seems a useful tool for elucidating cellular and molecular mechanisms involved in clinical disor-

Received October 24, 2000; accepted December 19, 2000.

Correspondence: Jean-Luc Daval, Ph.D., Jeune Equipe 2164 - Adaptation Néonatale \& Développement, Université Henri Poincaré-Nancy 1, 24-30 rue Lionnois, B.P. 3069, 54013 NANCY Cedex, France; e-mail: jldaval@u272.nancy.inserm.fr ders such as cerebral hypoxia $(5,6)$. Indeed, neuronal cells cultured in chemically defined medium have proven to mimic morphologic, electrophysiological, and neurochemical development and differentiation occurring in vivo $(7,8)$, and such a preparation provides the advantage of investigating cellular responses inherent to a single variable. By using cultured neurons from the developing rat forebrain as a model, we have previously demonstrated that transient oxygen deprivation may trigger neuronal death through an apoptotic process that requires specific and time-dependent changes in protein synthesis $(9,10)$, a conclusion supported by other studies $(6,11)$.

Bilirubin constitutes another potential cause of brain injury $(12,13)$. Hyperbilirubinemia is still a common concern in neonatology, especially in the care of low birth weight prema- 
ture infants. Interestingly, it has been reported that bilirubin can be present in the brains of infants who did not display significant elevations in serum bilirubin concentrations (14). In this respect, a recent study from our laboratory has shown in the same culture model that low concentration of unconjugated bilirubin (i.e. $0.5 \mu \mathrm{M}$ ) induces neuronal apoptosis involving caspase activation and that would be mediated by the NMDA glutamate receptor subtypes (15).

A number of neuropathological links between cerebral hypoxia and bilirubin have been described. Since the pioneering animal study by Lucey et al. (16) showing that antecedent hypoxic damage of the brain was prerequisite to the subsequent occurrence of kernicterus in the presence of hyperbilirubinemia, numerous clinical reports have emphasized the role of perinatal asphyxia, together with prematurity, acidosis, respiratory distress syndrome, and infection, as well as the use of certain drugs, as predisposing risk factors for bilirubin encephalopathy in newborn infants with low levels of serum bilirubin (17-19). Neurologic damage associated with perinatal asphyxia shows brain regional distribution and clinical manifestations somewhat similar to those observed in bilirubin encephalopathy (20-22). Furthermore, severe postnatal hypoxia has been reported to significantly increase bilirubin brain levels in newborn rats (23), with preferential bilirubin accumulation in cerebral areas corresponding to those more severely injured as a result of perinatal asphyxia (24). Also, the incidence of hypoxic encephalopathy in neonates was more elevated in kernicteric than in normal infants (25), suggesting that bilirubin may favor hypoxic brain damage.

Various signals may trigger neuronal apoptosis that results in similar final manifestations of cell death, and the available evidence indicates that several biochemical pathways may be involved in the apoptotic cascade (26). This suggests that distinct apoptosis-inducing agents may act complementarily and thus exert additive neurotoxic effects. The present study was therefore designed in an attempt to compare the influence of hypoxia and bilirubin on the outcome of neuronal cells in vitro, and analyze the cellular mechanisms that may contribute to the deleterious effects of low levels of bilirubin in conjunction with transient hypoxia.

\section{METHODS}

Neuronal cell culture. All animal experimentation was performed with the standards of animal care and housing, according to the NIH Guide for the Care and Use of Laboratory Animals, and was approved by the local institutional board (Bureau de la Protection Animale). Primary cultured neurons were obtained from 14-d-old rat embryo forebrains as previously described $(9,27)$. When they were in the proestrus period, as shown by the observation of daily vaginal smears, Sprague Dawley female rats (R. Janvier, Le Genest-St-Isle, France) were housed together with males for $24 \mathrm{~h}$, and pregnant dams were maintained in separate cages for $14 \mathrm{~d}$ under standard laboratory conditions on a $12 \mathrm{~h} / 12 \mathrm{~h}$ light/dark cycle (lights on at $0600 \mathrm{~h}$ ) with food and water available ad libitum.

Living embryos were excised by cesarean section performed under anesthesia with halothane. Whole embryos were placed in culture medium previously equilibrated at $37^{\circ} \mathrm{C}$ and consisting of a mixture of Dulbecco's modified Eagle's medium (DMEM) and Ham's F12 medium (50:50, ICN Pharmaceuticals, Costa Mesa, CA, U.S.A.) supplemented with 5\% inactivated FCS (Valbiotech, Paris, France). Forebrains were carefully collected, dissected free of meninges, and gently dispersed in culture medium. After centrifugation at $700 \times g$ for $10 \mathrm{~min}$, the pellet was redispersed in the same medium and passed through a $46-\mu \mathrm{m}$ pore size nylon mesh. Aliquots of the cell suspension were transferred into 35-mm Petri dishes (Falcon, Becton Dickinson, Le Pont-de-Claix, France) precoated with poly-L-lysine to obtain a final density of $10^{6}$ cells/dish. Cultures were then placed at $37^{\circ} \mathrm{C}$ in a humidified atmosphere of $95 \%$ air $/ 5 \% \mathrm{CO}_{2}$. The following day, the culture medium was replaced with a fresh hormonally defined serum-free medium consisting of the DMEM-Ham's F12 mixture enriched with human transferrin $(1 \mathrm{mM})$, bovine insulin $(1 \mathrm{mM})$, putrescine $(0.1 \mathrm{mM})$, progesterone $(10 \mathrm{nM})$, estradiol $(1 \mathrm{pM})$, and $\mathrm{Na}$ selenite $(30 \mathrm{nM})$, and also containing fibroblast growth factor $(2 \mathrm{ng} / \mathrm{mL})$ and epidermal growth factor $(10 \mathrm{ng} / \mathrm{mL})$ (Sigma Chemical Co., St. Louis, MO, U.S.A.). After an additional $2 \mathrm{~d}$, the culture medium was renewed with serum-free medium in the absence of growth factors.

Cell treatment with bilirubin and exposure to hypoxia. Six-day-old neuronal cell cultures were exposed to bilirubin for $4 \mathrm{~d}$. For this purpose, a stock solution was prepared in the dark at room temperature by dissolving $5 \mathrm{mg}$ bilirubin (Sigma Chemical Co.) in $0.5 \mathrm{~mL}$ of $0.1 \mathrm{M} \mathrm{NaOH}$. This solution was diluted at 1:20 in distilled water to obtain a solution containing $1 \mathrm{mM}$ bilirubin. After sterilization by filtration, the solution was finally diluted in serum-free culture medium to obtain a final bilirubin concentration of $0.5 \mu \mathrm{M}$, which has been previously shown to induce neurotoxic effects under our culture conditions, with an $\mathrm{ED}_{50}$ around $1 \mu \mathrm{M}$ (15). For subsequent cell treatment, the surrounding fluid of cultured neurons was discarded by aspiration and replaced with bilirubin-containing medium, which was not renewed over the ensuing 96-h incubation period. Control cultures were processed in parallel without addition of bilirubin.

The influence of transient hypoxia was also tested after $6 \mathrm{~d}$ in vitro in bilirubin-treated and -untreated cells by transferring the culture dishes for $6 \mathrm{~h}$ to a humidified incubation chamber thermoregulated at $37^{\circ} \mathrm{C}$ and flushed by a gas mixture consisting of $95 \% \mathrm{~N}_{2} / 5 \% \mathrm{CO}_{2}(9,27)$. Cultures were then returned for the next $96 \mathrm{~h}$ to normoxic atmosphere, whereas control dishes were constantly maintained under standard conditions. Reduction in oxygen delivery to the neurons was monitored by measuring oxygen pressure in samples of extracellular medium collected just before the beginning and then immediately at the end of the hypoxic insult, by means of a gas analyzer (Corning, Halstead, U.K.).

Analysis of neuronal outcome. Cell morphology was routinely assessed by phase-contrast microscopic observations by means of a Nikon Diaphot TMD (EstLab, Strasbourg, France). Cell viability was monitored at various time intervals by the spectrophotometric method using MTT, according to Hansen et al. (28). The assay is based on the cleavage of the tetrazolium salt by viable cells, and the reaction produces the accu- 
mulation of a water-insoluble formazan salt in cultured cells. Neurons were incubated for $3 \mathrm{~h}$ at $37^{\circ} \mathrm{C}$ with MTT (500 $\mu \mathrm{g} / \mathrm{mL}$, Sigma Chemical Co.), washed twice with ice-cold PBS, and lysed in DMSO, which solubilizes formazan for subsequent quantification. OD was measured at $519 \mathrm{~nm}$ and data were compared with those obtained from sister control cells.

Morphologic hallmarks of apoptosis and necrosis were analyzed as previously documented $(15,27,29,30)$ by staining fixed cultured cells for $10 \mathrm{~min}$ with the fluorescent dye DAPI (Sigma Chemical Co.) used at $0.5 \mu \mathrm{g} / \mathrm{mL}$ (31). Using this procedure, healthy neurons exhibit intact round-shaped nuclei with diffuse fluorescence, indicative of homogeneous chromatin. Necrotic neurons are characterized by highly refringent smaller nuclei with uniformly dispersed chromatin, whereas condensation and fragmentation of chromatin lead to typically shrunken nuclei in apoptotic neurons. Characteristic nuclei were scored under fluorescence microscopy (Zeiss Axioscop, EstLab, Strasbourg, France) at an excitation wavelength of 365 $\mathrm{nm}$ in at least three separate experiments by counting concerned cells in at least three distinct areas of 100 neurons per culture dish.

Rates of protein synthesis. Time-dependent biosynthetic rates of total proteins was monitored in neuronal cells by measuring the incorporation of radiolabeled L-leucine in the acid-insoluble cellular fraction (9). Before cell exposure to bilirubin or hypoxia, the culture medium was discarded, and the cells were loaded with $2 \mathrm{~mL}$ of fresh serum-free medium containing $0.5 \mu \mathrm{Ci} / \mathrm{mL}$ of $\mathrm{L}-\left[4,5-{ }^{3} \mathrm{H}\right]$ leucine (specific activity: $1.92 \mathrm{TBq} / \mathrm{mmol}$, New England Nuclear, Boston, MA, U.S.A.), the final concentration of the amino acid corresponding to 19.3 $\mathrm{mM}$. At various time intervals, the incorporation rate of leucine was measured. Cultures were washed twice with ice-cold saline and treated for 20 min with $10 \% \mathrm{TCA}$ at $4^{\circ} \mathrm{C}$. TCAsoluble material was then collected, and the cells were washed twice with $0.5 \mathrm{~mL}$ ethanol. One hundred-microliter samples were taken after ethanol evaporation under air stream for radioactivity determination using a scintillation spectrometer (Beckman, model LS-1801, Strasbourg, France). The TCAinsoluble fraction remaining on the bottom of the culture dishes was solubilized with $1 \mathrm{~mL}$ of $1 \mathrm{M} \mathrm{NaOH}$ and aliquots were used for scintillation counting and measurement of protein concentrations by the Bradford method (32).

Glucose transport and incorporation. Functional activity of cultured neurons was evaluated by measuring specific transport and incorporation of the glucose analogue, $2-\mathrm{D}-\left[{ }^{3} \mathrm{H}\right]$ deoxyglucose $\left(\left[{ }^{3} \mathrm{H}\right] 2-\mathrm{DG}\right)$, into the cells (33). Culture dishes were washed twice in a HEPES-buffered Krebs-Ringer solution (125 $\mathrm{mM} \mathrm{NaCl}, 4.8 \mathrm{mM} \mathrm{KCl}, 1.2 \mathrm{mM} \mathrm{MgSO}_{4}, 1.3 \mathrm{mM} \mathrm{CaCl}_{2}, 1.2$ $\mathrm{mM} \mathrm{KH} \mathrm{PO}_{4}, 25 \mathrm{mM}$ HEPES, $\mathrm{pH}$ 7.4) and incubated in the buffer solution for $15 \mathrm{~min}$ at $37^{\circ} \mathrm{C}$. The medium was then discarded and the assay was initiated by adding $1.5 \mathrm{~mL}$ of the Krebs-Ringer medium containing $1 \mathrm{mM}\left[{ }^{3} \mathrm{H}\right] 2-\mathrm{DG}$ (960 GBq/ mmol, New England Nuclear). After a 30-min incubation, the cultures were rapidly washed three times with physiologic saline, dried, and solubilized in $1 \mathrm{~mL}$ of $1 \mathrm{M} \mathrm{NaOH}$. Samples were taken for scintillation counting and measurement of protein contents. Nonspecific uptake of $\left[{ }^{3} \mathrm{H}\right] 2-\mathrm{DG}$ was as- sessed by measuring the residual radioactivity in the cultured cells by the same experimental procedure performed in the additional presence of $100 \mathrm{mM}$ D-glucose.

Analysis of free radical generation. In an attempt to evaluate the influence of bilirubin on the amount of reactive oxygen species that can be generated by hypoxia, intracellular levels of free radicals were monitored in individual cells by flow cytometry using the fluorogenic dye DHR, which can easily cross cell membranes and becomes fluorescent upon oxidation by reactive oxygen species, mainly superoxide, to finally generate rhodamine $123(34,35)$. Neuronal cells were covered with 1 $\mathrm{mL}$ of fresh serum-free medium containing $150 \mu \mathrm{M}$ DHR (Molecular Probes, Eugene, OR, U.S.A.) from a 15-mM stock solution in dimethylformamide. Culture dishes were then replaced in the incubator at $37^{\circ} \mathrm{C}$ for $5 \mathrm{~min}$, and neurons were suspended by slow horizontal agitation in the presence of $1 \mathrm{~mL}$ PBS containing $0.5 \%$ trypsin. The effects of trypsin were then blocked by the addition of $1 \mathrm{~mL}$ PBS enriched with $0.5 \mathrm{mM}$ $\mathrm{Ca}^{2+} / \mathrm{Mg}^{2+}$, and the cell suspension was collected in a polypropylene tube stored on ice before analysis by means of a Coultronics Epics XL (Margency, France) flow cytometer equipped with an argon laser. The green intracellular fluorescence of rhodamine 123 was measured at an excitation wavelength of $488 \mathrm{~nm}$ by studying at least 25,000 living cells for each assay.

\section{RESULTS}

Cell viability and nuclear morphology. At $6 \mathrm{~d}$ in vitro, cells cultured from the embryonic rat forebrain showed polygonal perikarya interconnected by a dense fiber network. Immunohistochemical characterization by using antibodies raised against neuron-specific enolase (NSE) and glial fibrillary acidic protein (GFAP) confirmed that such preparations were highly enriched in neurons, depicting $92.5 \pm 2.8 \%$ of NSE-positive cells, with $7.6 \pm 1.6 \%$ of GFAP-positive cells (not shown).

Transient exposure to anaerobic gas mixture routinely reduced the $\mathrm{PO}_{2}$ in the culture medium by $78 \pm 3 \%$, compared with control cultures maintained in normoxia. Consecutively to the hypoxic stress, neuronal alterations could be first noticed by $48 \mathrm{~h}$ after reoxygenation, as already reported $(9,27)$. At $96 \mathrm{~h}$ postreoxygenation, analysis of cell viability showed a $23 \%$ reduction of the number of living cells, compared with matched control neurons (Fig. 1). Nuclear staining with DAPI confirmed the higher increase in the number of apoptotic rather than necrotic neurons by the end of the experimental period (Table 1).

At the concentration of $0.5 \mu \mathrm{M}$, bilirubin induced a delayed and progressive decline in the number of living neurons that finally reached $24.5 \%$ below controls at $96 \mathrm{~h}$, as depicted by the MTT assay (Fig. 1). As previously reported (15), a significant number of cell nuclei stained by the fluorescent dye DAPI exhibited characteristic morphologic features of apoptosis, such as chromatin condensation. Necrotic cells could be additionally observed in bilirubin-treated cultures, but the percentage of apoptotic nuclei increased more markedly (Table 1).

Finally, when cultured cells were exposed to hypoxia in the presence of bilirubin, neuronal injury was more evident than 
with either treatment taken separately (Fig. 1, Table 1). Neuronal loss reached $34 \%$, and genomic DNA staining by DAPI revealed the presence of $23 \%$ of neurons exhibiting evident signs of apoptosis.

Protein synthesis. In control normoxic cells, radioactivity measured in the acid-precipitable fraction, which reflects biosynthetic activity, progressively increased as a function of time after cell loading with L- $\left[{ }^{3} \mathrm{H}\right]$ leucine. It varied from $2728 \pm$ 198 to $274,450 \pm 7,820 \mathrm{dpm} /$ dish between $1 \mathrm{~h}$ and $96 \mathrm{~h}$. Hypoxia-induced cell damage was accompanied by characteristic changes in the time course of $\left[{ }^{3} \mathrm{H}\right]$ leucine incorporation rates (Fig. 2). By $1 \mathrm{~h}$ after the onset of hypoxia and then at $48 \mathrm{~h}$ after reoxygenation, two distinct marked increases in protein synthesis in hypoxic neurons ( $+44 \%$ and $+50 \%$, respectively) were recorded. Thereafter, rates of protein synthesis declined, in parallel with the appearance of morphologic signs of cell injury. Similar temporal profiles of synthesis were recorded in cultured neurons exposed either to hypoxia in the presence of bilirubin or to bilirubin alone, although the second peak of protein synthesis was more prolonged in the latter situations (Fig. 2). These data suggest that, in all cases, neuronal damage required de novo protein synthesis, as previously shown in other apoptosis paradigms (36-38). This was supported by the significant protective effects of the protein synthesis inhibitor CHX in both hypoxia- and bilirubin-treated neurons. In the presence of CHX $(1 \mu \mathrm{M})$, the final rate of viable neuronal cells was in the range of that measured in cultures exposed to CHX alone (Table 1). Moreover, whereas the number of necrotic cells recorded with $\mathrm{CHX}$ tended to be more elevated than in control cultures, the synthesis inhibitor abolished nucleic morphologic features of apoptosis in culture preparations exposed to hypoxia or bilirubin.

2-DG transport and incorporation and free radical generation. Control values of $\left[{ }^{3} \mathrm{H}\right] 2-\mathrm{DG}-$ specific uptake in cultured neurons were remarkably stable at the various time points studied over the experimental period. They corresponded to $112.6 \pm 2.7$ and $119.4 \pm 1.8 \mathrm{nmol}$ deoxyglucose per $\mathrm{mg}$ of protein at $6 \mathrm{~h}$ and $96 \mathrm{~h}$, respectively. As shown in Figure 3, the

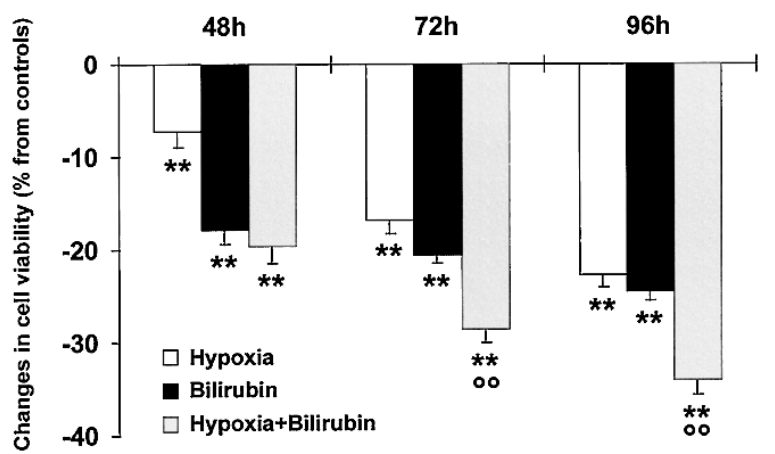

Figure 1. Effects of hypoxia or/and bilirubin on cell viability monitored as a function of time by the MTT method. Data were obtained from at least three separate experiments using $10-15$ dishes per time point for each treatment, and are expressed as mean percentage of changes $( \pm$ SD) compared with sister control cultures maintained in standard normoxic conditions. Statistically significant difference from controls: ${ }^{*} p<0.05$ and ${ }^{* *} p<0.01$; statistically significant difference from hypoxia alone: ${ }^{\circ} p<0.01$ (Dunnett's test for multiple comparisons).
Table 1. Neuronal viability and nuclear morphology scored at $96 \mathrm{~h}$ after exposure to hypoxia, bilirubin, or both treatments-effects of CHX and glutamate receptor antagonists

\begin{tabular}{|c|c|c|c|}
\hline & $\begin{array}{l}\text { Viability score } \\
\text { (\% from controls) }\end{array}$ & $\begin{array}{l}\text { Necrosis (\% of } \\
\text { total neurons) }\end{array}$ & $\begin{array}{c}\text { Apoptosis (\% of } \\
\text { total neurons) }\end{array}$ \\
\hline Controls & $100.0 \pm 6.9$ & $5.2 \pm 1.4$ & $2.4 \pm 0.8$ \\
\hline$+1 \mu \mathrm{M}$ CHX & $92.2 \pm 4.6$ & $9.3 \pm 2.6^{*}$ & $3.0 \pm 0.9$ \\
\hline$+10 \mu \mathrm{M}$ MK-801 & $97.6 \pm 3.5$ & $5.8 \pm 0.9$ & $2.7 \pm 0.4$ \\
\hline$+10 \mu \mathrm{M}$ NBQX & $96.4 \pm 4.7$ & $6.0 \pm 1.2$ & $2.9 \pm 0.6$ \\
\hline Hypoxia & $77.3 \pm 2.1^{* *}$ & $9.2 \pm 0.6^{* *}$ & $13.4 \pm 1.1^{* *}$ \\
\hline$+1 \mu \mathrm{M} \mathrm{CHX}$ & $90.5 \pm 5.1 \dagger \dagger$ & $11.1 \pm 2.2^{* *}$ & $2.8 \pm 1.0 \dagger \dagger$ \\
\hline$+10 \mu \mathrm{M} \mathrm{MK}-801$ & $78.9 \pm 4.4 * *$ & $8.8 \pm 0.6^{* *}$ & $10.3 \pm 1.7^{* *}$ \\
\hline$+10 \mu \mathrm{M}$ NBQX & $74.3 \pm 3.0^{* *}$ & $9.1 \pm 1.1 *$ & $12.8 \pm 1.3^{* *}$ \\
\hline Bilirubin & $75.5 \pm 1.9 * *$ & $12.0 \pm 1.3^{* *}$ & $16.2 \pm 1.5^{* *}$ \\
\hline$+1 \mu \mathrm{M} \mathrm{CHX}$ & $90.6 \pm 4.9$ & $13.3 \pm 1.8^{*}$ & $2.9 \pm 0.5$ \\
\hline$+10 \mu \mathrm{M} \mathrm{MK}-801$ & $97.8 \pm 2.3$ & $6.9 \pm 1.0$ & $3.8 \pm 0.6$ \\
\hline$+10 \mu \mathrm{M}$ NBQX & $76.0 \pm 3.6^{* *}$ & $14.0 \pm 1.6^{* *}$ & $14.7 \pm 0.9 * *$ \\
\hline Hypoxia + Bilirubin & $66.0 \pm 2.5^{* *}, \dagger \dagger$ & $16.9 \pm 3.3^{* *}, \dagger \dagger$ & $22.6 \pm 3.1^{* *}, \dagger \dagger$ \\
\hline$+10 \mu \mathrm{M}$ MK-801 & $88.8 \pm 2.8^{* *}$ & $8.4 \pm 0.8^{*}$ & $8.9 \pm 0.7^{* *}$ \\
\hline$+10 \mu \mathrm{M}$ NBQX & $69.1 \pm 3.7 * *$ & $17.1 \pm 2.9^{* *}$ & $20.5 \pm 2.8^{* *}$ \\
\hline
\end{tabular}

Cell viability was assessed by using MTT, whereas healthy, necrotic, and apoptotic neurons were scored by fluorescence microscopy after nuclear staining by DAPI. Data are reported as means \pm SD obtained from three to five separate experiments. CHX or glutamate receptor antagonists (MK-801 and NBQX) were added to the culture medium before exposure to hypoxia or/and bilirubin. Statistically significant difference versus the corresponding pharmacologically treated control: $* p<0.05$ and $* * p<0.01$; statistically significant difference versus hypoxia alone: $\dagger \dagger p<0.01$ (Dunnett's test for multiple comparisons).

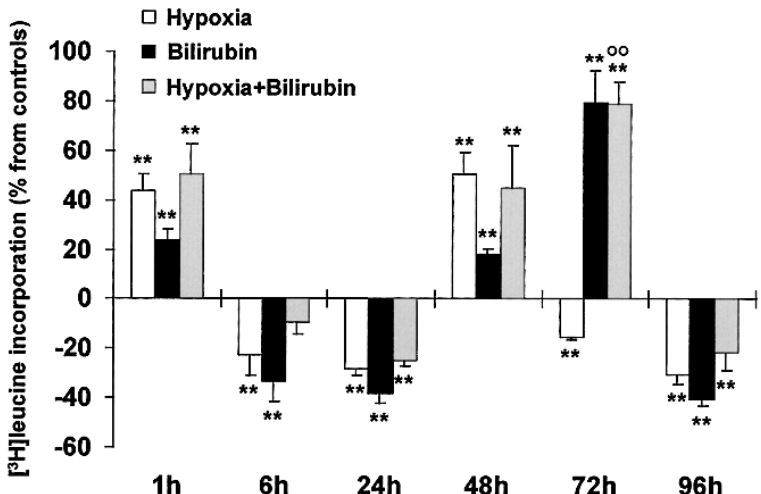

Figure 2. Time course of specific changes in $\mathrm{L}-\left[{ }^{3} \mathrm{H}\right]$ leucine incorporation rates into acid-insoluble fractions of neurons submitted to hypoxia or/and bilirubin. Data were obtained from at least three separate experiments using $10-15$ dishes per time point, and are expressed as mean percentage of changes $( \pm \mathrm{SD})$ compared with sister control cultures. Statistically significant difference from controls: ${ }^{* *} p<0.01$; statistically significant difference from hypoxia alone: ${ }^{\circ 0} p<0.01$ (Dunnett's test for multiple comparisons).

uptake of $\left[{ }^{3} \mathrm{H}\right] 2-\mathrm{DG}$ was significantly increased following hypoxia, and such an apparent hypermetabolism lasted for at least $24 \mathrm{~h}$ after reoxygenation. Thereafter, $\left[{ }^{3} \mathrm{H}\right] 2-\mathrm{DG}$ uptake progressively decreased concomitantly with the appearance of morphologic alterations, to finally reach $42 \%$ below control values at $96 \mathrm{~h}$ posthypoxia. By contrast, bilirubin led to a continuous, significant, and long-lasting reduction of $\left[{ }^{3} \mathrm{H}\right] 2-$ DG transport and incorporation into the cultured cells. When neurons were submitted to combined treatments, $\left[{ }^{3} \mathrm{H}\right] 2-\mathrm{DG}$ 


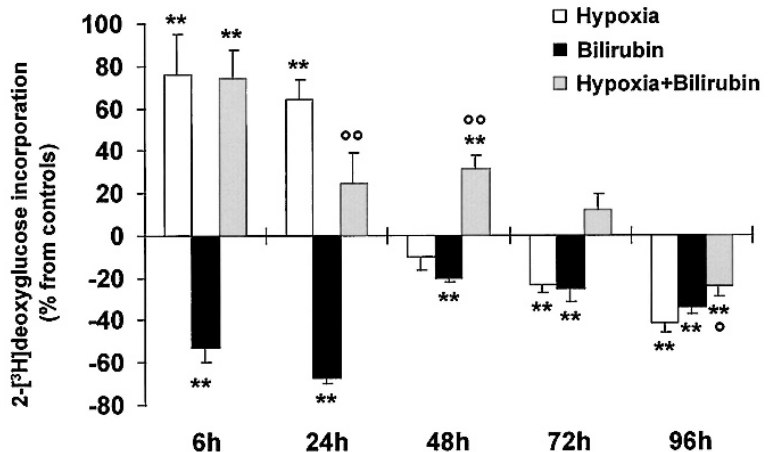

Figure 3. Time course of specific changes in specific transport and incorporation of 2-[ $\left[{ }^{3} \mathrm{H}\right]$-D-deoxyglucose into cultured neuronal cells exposed to hypoxia or/and bilirubin. Data were obtained from at least three separate experiments using 10-25 dishes per time point, and are expressed as mean percentage of changes $( \pm \mathrm{SD})$ compared with sister control cultures. Statistically significant difference from controls: $* * p<0.01$; statistically significant difference from hypoxia alone: ${ }^{\circ} p<0.05$ and ${ }^{\circ \circ} p<0.01$ (Dunnett's test for multiple comparisons).

uptake was increased by the end of the hypoxic episode, as observed with hypoxia alone, but remained elevated until $72 \mathrm{~h}$ postreoxygenation.

Therefore, one may consider that the additional presence of bilirubin helps to maintain glucose transport and incorporation, a process necessary for energy metabolism, in hypoxic neurons. In an attempt to explain this unexpected observation, and providing that bilirubin has been suspected to be a free radical scavenger $(39,40)$, we analyzed the intracellular generation of free radicals in our culture model. At the concentration used, bilirubin by itself was devoid of effect on the basal radical generation monitored by the mitochondrial probe DHR (Fig. 4). Whereas the neuronal production of free radicals was transiently increased in response to hypoxia, no attenuation could be obtained in the additional presence of bilirubin

Effects of glutamate receptor antagonists. Because earlier studies have implicated glutamate in bilirubin neurotoxicity $(15,41,42)$, the influence of glutamate receptor antagonists was also tested. For this purpose, the two glutamate receptor

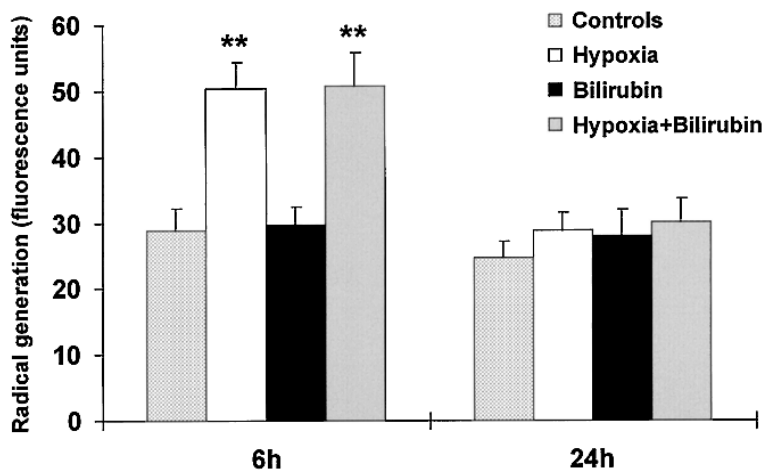

Figure 4. Effects of hypoxia and bilirubin on intracellular free radical production detected by flow cytometry using the fluorescent dye DHR. The data are reported as mean fluorescence units recorded at $6 \mathrm{~h}$ (time corresponding at the reoxygenation time) and then $24 \mathrm{~h}$ later in treated neurons as well as in their matched controls. Measurements were performed in two separate experiments, and the samples were run in duplicate for each time point. Statistically significant difference from controls: ${ }^{* *} p<0.01$ ( $t$ test). antagonists MK-801 (10 $\mu \mathrm{M}$, Tocris, Bristol, U.K.) and NBQX (10 $\mu \mathrm{M}$, Tocris), which are known to be selective for NMDA and non-NMDA receptors, respectively, were added to the culture medium just before exposure to bilirubin or/and hypoxia and they were then left for $6 \mathrm{~h}$.

Whereas these compounds had no effects by themselves on neuronal outcome, the presence of the non-NMDA receptor antagonist NBQX did not exert any influence on the consequences of either hypoxia, bilirubin, or the combination of both treatments (Table 1). Regarding the NMDA receptor antagonist MK-801, its action varied according to the cell treatment (Table 1). When cultured neurons were subjected to hypoxia alone, no significant effect of MK-801 could be observed, whereas the compound fully protected neuronal cells against the toxic effects of bilirubin. Finally, MK- 801 had only partial - but significant - protective effects on both the vital score and the percentage of apoptotic nuclei in the case of exposure to the combination hypoxia plus bilirubin.

\section{DISCUSSION}

Whereas the data reported herein confirm the recent demonstration of bilirubin-induced neuronal apoptosis in the developing brain (15), they show that the presence of low concentrations of unconjugated bilirubin, which displays a high affinity for phospholipids of neuronal cell membranes $(43,44)$, can potentiate cerebral damage resulting from transient hypoxia, and thus may contribute to the associated acute and subsequent long-term disturbances of the CNS $(1,2)$. Furthermore, cumulative toxic effects of bilirubin and hypoxia suggest the involvement of partly different mechanisms of action at the cellular level.

Following exposure to either hypoxia or bilirubin, neuronal death was dependent upon the regulation of protein synthesis. The recorded changes in the rates of protein synthesis preceding apoptotic death of cells exposed to hypoxia and/or bilirubin probably reflect selective induction or repression of specific gene products that are directly involved in the regulation of the apoptotic cascade $(9,27,45,46)$. However, the variationsboth in magnitude and time-observed in leucine incorporation between the different treatments suggest a possible specificity in the genetic control of neuronal outcome according to the nature of the stress. In other words, protein synthesis triggered by bilirubin may partly differ from that triggered by hypoxia, and this might render bilirubin-treated neurons more sensitive to the hypoxic insult. It would be therefore of interest to address this question in a future study by analyzing the profile of key apoptosis-related proteins in cultured neurons exposed to bilirubin.

Changes between hypoxia- and bilirubin-treated neuronal cells were more strikingly different with regard to energy metabolism, as reflected by glucose uptake and incorporation. Although not shown in the present study, there is, under severe hypoxic conditions, a rapid failure in ATP generation, resulting in transient activation of anaerobic glycolysis. It has been demonstrated that glucose is the primary energy substrate for the brain in fetuses and newborns as well as in adults $(47,48)$. Although other substrates such as ketone bodies may provide 
alternate fuels in some pathologic conditions, their consumption requires oxygen and, thus, only glucose is capable of sustaining brain energy metabolism in hypoxia via anaerobic glycolysis. Therefore, the transient increase in $\left[{ }^{3} \mathrm{H}\right]$ deoxyglucose incorporation into cultured cells that was observed after exposure to hypoxia may reflect the activation of glycolysis in vitro, as previously reported in the same experimental model (33), and in vivo (49). Thereafter, energy metabolism progressively declined concomitantly to cell degeneration. By contrast, a significant reduction of glucose uptake was continuously recorded in bilirubin-treated neurons. Bilirubin has been reported to disrupt energy metabolism (50), and our data are in good agreement with in vivo studies in developing rats that have shown that hyperbilirubinemia induces a widespread decrease in cerebral metabolic rates for glucose, with prominent effects in brain areas known to preferentially accumulate bilirubin in kernicteric human babies (51), as well as in cerebral structures, the function of which is commonly altered (52). Finally, the presence of bilirubin in the culture medium of hypoxic neurons led to a metabolic profile closer to that recorded after hypoxia alone. Unexpectedly, the incorporation of deoxyglucose seemed to be preserved at $48 \mathrm{~h}$ and even at $72 \mathrm{~h}$ posthypoxia. However, the presence of bilirubin during the hypoxic insult failed to reduce the generation of reactive oxygen species. Although these results are still preliminary and remain to be confirmed, including by the analysis of radicals that may have diffused in the extracellular medium (33), they do not suggest a scavenging role for bilirubin in its apparent metabolic effects in hypoxic neurons, and the mechanism of action remains a matter of speculation.

Several lines of evidence suggest that the brain-damaging action of bilirubin requires the participation of glutamate toxicity $(15,41,42)$. In this respect, our observations that MK801, but not NBQX, is able to prevent bilirubin-induced cell injury in cultured neurons confirm that the effects of bilirubin certainly imply the activation of NMDA receptors. Conversely, cultured neurons were not rescued from hypoxia by the presence of glutamate receptor antagonists. These findings are consistent with earlier studies that demonstrated a lack of correlation between the effects of exposure to glutamate and those of transient hypoxia in immature neurons $(53,54)$. Although the presence of functional receptors for glutamate, including NMDA receptors, has been demonstrated in cultured neurons at the corresponding maturational stage (55), these neurons, in contrast to more mature cells, are not sensitive to toxic concentrations of either glutamate or one of its derivatives, such as NMDA, kainate, or AMPA ( $\alpha$-amino-3-hydroxy5-methyl-4-isoxazole propionate) $(54,56)$. Pharmacological studies have revealed that a loss of protein kinase $\mathrm{C}$ activity is necessary for glutamate-mediated induction of neurotoxicity. This phenomenon appears to be an essential element of the excitotoxic death of neuronal cells, and cellular events responsible for linking glutamate-associated $\mathrm{Ca}^{2+}$ influx to protein kinase $\mathrm{C}$ inactivation are undeveloped in such immature neurons in vitro $(53,54,57)$. Specifically in our model, we have previously shown that neurons became vulnerable to the application of glutamate when they were co-exposed to $30 \mathrm{nM}$ staurosporine, a protein kinase $\mathrm{C}$ inhibitor, and that cells can be rescued by glutamate receptor antagonists $(54,56)$. On the other hand, accumulative evidence has been provided to demonstrate that bilirubin inhibits protein kinase $\mathrm{C}$ activity with subsequent blockade of protein kinase C-mediated phosphorylation of endogenous substrates in various tissue systems. This process has been reported to play a role in the pathogenesis of bilirubin toxicity $(58,59)$. Accordingly, bilirubin, through its direct action on protein kinase $\mathrm{C}$, may render the neurons sensitive to glutamate toxicity (15), and such properties may account, at least partly, for the potentiation of hypoxia effects by bilirubin.

In conclusion, whereas the toxic effects of bilirubin involve alterations of the rates of neuronal protein synthesis and energy metabolism as well as subsequent apoptotic cell death, the present study strongly suggests that low levels of unconjugated bilirubin may enhance hypoxic damage in the developing brain by allowing the additional recruitment of glutamate neurotoxicity through the activation of NMDA receptors.

Acknowledgment. The authors thank Dr. Mireille Donner (faculté de Médecine, Nancy) for allowing free access to fluorescence microscopy. The authors wish to express their gratitude to Mrs Catherine Charoy for her generous support.

\section{REFERENCES}

1. Mutch L, Alberman E, Hagberg B, Kodoma K, Perat MV 1992 Cerebral palsy epidemiology: where are we and where are we going? Dev Med Child Neurol 34:547-551

2. Patel J, Edwards AD 1997 Prediction of outcome after perinatal asphyxia. Curr Opin Pediatr 9:128-132

3. Friedman JE, Haddad GG 1993 Major differences in $\mathrm{Ca}^{2+} \mathrm{i}$ response to anoxia between neonatal and adult rat CA1 neurons: role of $\mathrm{Ca}^{2+} \mathrm{O}$ and $\mathrm{Na}^{+} \mathrm{o}$. J Neurosci 13:63-72

4. Taniguchi T, Fukunaga R, Matsuoka Y, Terai K, Tooyama I, Kimura H 1994 Delayed expression of c-fos protein in rat hippocampus and cerebral cortex following transient in vivo exposure to hypoxia. Brain Res 640:119-125

5. Rothman SM 1983 Synaptic activity mediates cell death of hypoxic neurons. Science 220:536-537

6. Banasiak KJ, Haddad GG 1998 Hypoxia-induced apoptosis: effect of hypoxic severity and role of p53 in neuronal cell death. Brain Res 797:295-304

7. Dichter MA 1978 Rat cortical neurons in cell culture: culture methods, cell morphology, electrophysiology and synapse formation. Brain Res 149:279-293

8. Laerum OD, Steinsvag S, Bjerkvig R 1985 Cell and tissue culture of the central nervous system: recent developments and current applications. Acta Neurol Scand 72:529-549

9. Bossenmeyer C, Chihab R, Muller S, Schroeder H, Daval JL 1998 Hypoxia/ reoxygenation induces apoptosis through biphasic induction of protein synthesis in central neurons. Brain Res 787:107-116

10. Chihab R, Ferry C, Koziel V, Monin P, Daval JL 1998 Sequential activation of activator protein-1-related transcription factors and JNK protein kinases may contribute to apoptotic death induced by transient hypoxia in developing brain neurons. Mol Brain Res 63:105-120

11. Tamatani M, Mitsuda N, Matsuzaki H, Okado H, Miyake S, Vitek MP, Yamaguchi A, Tohyama M 2000 A pathway of neuronal apoptosis induced by hypoxia/ reoxygenation: roles of nuclear factor-kappa B and Bcl-2. J Neurochem 75:683-693

12. Maisels MJ 1994 Bilirubin. In: Avery GB, Fletcher MA, MacDonald MG (eds) Neonatology: Pathophysiology and Management of the Newborn, 4th ed. JB Lippincott, Philadelphia, pp 630-725

13. Volpe JJ 1995 Bilirubin and brain injury. In: Volpe JJ (ed) Neurology of the Newborn. Saunders, Philadelphia, pp 490-514

14. Ahdab-Barmada M, Moossy J 1982 The neuropathology of kernicterus in the premature infant: diagnostic problems. J Neuropathol Exp Neurol 43:45-56

15. Grojean S, Koziel V, Vert P, Daval JL 2000 Bilirubin induces apoptosis via activation of NMDA receptors in developing rat brain neurons. Exp Neurol 166:334-341

16. Lucey JF, Hibbard E, Behrman RE, Esquivel de Gallardo FO, Windle WF 1964 Kernicterus in asphyxiated newborn Rhesus monkey. Exp Neurol 9:43-49

17. Ackerman BD, Dyer GI, Leydorf MM 1970 Hyperbilirubinemia and kernicterus in small premature infants. Pediatrics 45:918-925

18. Cashore WJ, Oh W 1982 Unbound bilirubin and kernicterus in low-birth-weight infants. Pediatrics 69:481-485

19. Graziani LJ, Mitchell DG, Kornhauser M, Pidcock FS, Merton DA, Stanley C, McKee LE 1992 Neurodevelopment of preterm infants: neonatal neurosonographic and serum bilirubin studies. Pediatrics 89:229-234. 
20. Cowger ML 1973 Bilirubin encephalopathy. In: Gaull GE (ed) Brain Dysfunction. Plenum Press, New York, pp 265-293

21. Myers RE 1979 A unitary theory of causation of anoxia and hypoxia brain pathology. In: Fahn C, Davis JN, Rowland LP (eds) Cerebral Hypoxia and Its Consequences. Advances in Neurology, Vol 26. Raven Press New York, pp 195-213

22. Odell GB 1981 Neonatal Hyperbilirubinemia. Grune and Stratton, New York

23. Mayor Jr F, Pagés M, Diez-Guerra J, Valdivieso F, Mayor F 1985 Effect of postnata anoxia on bilirubin levels in rat brain. Pediatr Res 19:231-236

24. Vannucci RC, Plum F 1975 Pathophysiology of perinatal hypoxic-ischemic brain damage. In: Gaull GE (ed) Biology of Brain Dysfunction. Plenum Press, New York, pp $1-45$

25. Kim MH, Yoon JJ, Sher J, Brown AK 1980 Lack of predictive indices in kernicterus: a comparison of clinical and pathologic factors in infants with or without kernicterus. Pediatrics 66:852-858

26. Sastry PS, Rao KS 2000 Apoptosis and the nervous system. J Neurochem 74:1-20

27. Bossenmeyer-Pourié C, Koziel V, Daval JL 2000 Effects of hypothermia on hypoxiainduced apoptosis in cultured neurons from developing rat forebrain: comparison with preconditioning. Pediatr Res 47:385-391

28. Hansen MB, Nielsen SE, Berg K 1989 Re-examination and further development of a precise and rapid dye method for measuring cell growth/cell kill. J Immunol Meth 119:203-210

29. Gschwind M, Huber G 1997 Detection of apoptotic or necrotic death in neuronal cells by morphological, biochemical, and molecular analysis. In: Poirier J (ed) Apoptosis Techniques and Protocols, Neuromethods, Vol 29. Humana Press, Totowa, pp 13-31

30. Park DS, Morris EJ, Greene LA, Geller HM 1997 G1/S cell cycle blockers and inhibitors of cyclin-dependent kinases suppress camptothecin-induced neuronal apoptosis. J Neurosci 17:1256-1270

31. Wolvetang EJ, Johnson KL Krauer K, Ralph SJ, Linnane AW 1994 Mitochondrial respiratory chain inhibitors induce apoptosis. FEBS Lett 339:40-44

32. Bradford MM 1976 A rapid and sensitive method for the quantitation of microgram quantities of proteins utilizing the principle of protein-dye binding. Anal Biochem $72: 248-254$

33. Oillet J, Koziel V, Vert P, Daval JL 1996 Influence of post-hypoxia reoxygenation conditions on energy metabolism and superoxide production in cultured neurons from the rat forebrain. Pediatr Res 39:598-603

34. Rothe G, Emmendorffer A, Oser A, Roesler J, Valet G 1991 Flow cytometric measurement of the respiratory burst activity of phagocytes using dihydrorhodamine 123. J Immunol Meth 138:133-135

35. Bueb JL, Gallois A, Schneider JC, Parini JP, Tschirhart E 1995 A double-labelling fluorescent assay for concomitant measurements of $\left[\mathrm{Ca}^{2+}\right] \mathrm{i}$ and $\mathrm{O}_{2}$ production in human macrophages. Biochim Biophys Acta 1244:79-84

36. Shigeno T, Yamasaki Y, Kato G, Kusaka K, Mima T, Takakura K, Graham DI, Furukawa S 1990 Reduction of delayed neuronal death by inhibition of protein synthesis. Neurosci Lett 120:117-119

37. Johnson EM, Deckwerth TL 1993 Molecular mechanisms of developmental neuronal death. Annu Rev Neurosci 16:31-46

38. Pittman RN, Wang S, DiBenedetto AJ, Mills JC 1993 A system for characterizing cellular and molecular events in programmed neuronal cell death. J Neurosci 13:3669-3680

39. Stocker R, Yamamoto Y, McDonagh AF, Glazer AN, Ames BN 1987 Bilirubin is an antioxidant of possible physiological importance. Science 235:1043-1046

40. Dennery PA, McDonagh AF, Spitz DR, Rodgers PA, Stevenson DK 1995 Hyperbilirubinemia results in reduced oxidative injury in neonatal gunn rats exposed to hyperoxia. Free Rad Biol Med 19:395-404
41. Hoffman DJ, Zanelli SA, Kubin J, Mishra OP, Delivoria-Papadopoulos M 1996 The in vivo effect of bilirubin on the $N$-methyl-D-aspartate receptor/ion channel complex in the brains of newborn piglets. Pediatr Res 40:804-808

42. McDonald JW, Shapiro SM, Silverstein FS, Johnston MV 1998 Role of glutamate receptor mediated excitotoxicity in bilirubin-induced brain injury in the Gunn rat model. Exp Neurol 150:21-29

43. Brodersen R 1979 Bilirubin: solubility and interaction with albumin and phospholipid. J Biol Chem 254:2364-2369

44. Notter MFD, Kendig JW 1986 Differential sensitivity of neural cells to bilirubin toxicity. Exp Neurol 94:670-682

45. Bossenmeyer-Pourié C, Koziel V, Daval JL 1999 CPP32/caspase-3-like proteases in hypoxia-induced apoptosis in developing brain neurons. Mol Brain Res 71:225-237

46. Bossenmeyer-Pourié C, Koziel V, Daval JL 2000 Involvement of caspase-1 proteases in hypoxic brain injury. Effects of their inhibitors in developing neurons. Neuroscience 95:1157-1165

47. Jones MD, Burd LI, Makowski EI, Meschia G, Battaglia FC 1975 Cerebral metabolism in sheep: a comparative study in the adult, the lamb, and the fetus. Am J Physiol 229:235-239

48. Settergren G, Lindblad BS, Persson B 1980 Cerebral blood flow and exchange of oxygen, glucose, ketone bodies, lactate, pyruvate and amino acids in anesthetized children. Acta Pediatr Scand 69:457-465

49. Bômont L, Bilger A, Boyet S, Vert P, Nehlig A 1992 Acute hypoxia induces specific changes in local cerebral glucose utilization at different postnatal ages in the rat. Dev Brain Res 66:33-45

50. Ives NK, Cox DWG, Gardiner RM, Bachelard HS 1988 The effects of bilirubin on brain energy metabolism during normoxia and hypoxia: an in vitro study using ${ }^{31} \mathrm{P}$ nuclear magnetic resonance spectroscopy. Pediatr Res 23:569-573

51. Roger C, Koziel V, Vert P, Nehlig A 1995 Regional cerebral metabolic consequences of bilirubin in rat depend upon post-gestational age at the time of hyperbilirubinemia. Dev Brain Res 87:194-202

52. Roger C, Koziel V, Vert P, Nehlig A 1993 Effects of bilirubin infusion on local cerebral glucose utilization in the immature rat. Dev Brain Res 76:115-130

53. Durkin JP, Tremblay R, Chakravarthy B, Mealing G, Morley P, Song D 1997 Evidence that the early loss of membrane protein kinase $\mathrm{C}$ is a necessary step in the excitatory amino acid-induced death of primary cortical neurons. J Neurochem 68:1400-1412

54. Chihab R, Bossenmeyer C, Oillet J, Daval JL 1998 Lack of correlation between the effects of transient exposure to glutamate and those of hypoxia/reoxygenation in immature neurons in vitro. J Neurochem 71:1177-1186

55. Oillet J, Nicolas F, Koziel V, Daval JL 1995 Analysis of glutamate receptors in primary cultured neurons from fetal rat forebrain. Neurochem Res 20:761-768

56. Chihab R, Oillet J, Bossenmeyer C, Daval JL 1998 Glutamate triggers cell death specifically in mature central neurons through a necrotic process. Mol Gen Metab 63:142-147

57. Durkin JP, Tremblay R, Buchan A, Blosser J, Chakravarthy B, Mealing G, Morley P, Song D 1996 An early loss in membrane protein kinase C activity precedes the excitatory amino acid-induced death of primary cortical neurons. J Neurochem 66:951-962

58. Sano K, Nakamura H, Matsuo T 1985 Mode of inhibitory action of bilirubin on protein kinase C. Pediatr Res 19:587-590

59. Amit $\mathrm{Y}$, Boneh A 1993 Bilirubin inhibits protein kinase $\mathrm{C}$ activity and protein kinase C-mediated phosphorylation of endogenous substrates in human skin fibroblasts. Clin Chim Acta 223:103-111 